PAPER

\title{
Clinical and radiological predictors of recanalisation and outcome of 40 patients with acute basilar artery occlusion treated with intra-arterial thrombolysis
}

\author{
M Arnold, K Nedeltchev, G Schroth, R W Baumgartner, L Remonda, T J Loher, F Stepper, \\ M Sturzenegger, B Schuknecht, H P Mattle
}

See Editorial Commentary, p 811

J Neurol Neurosurg Psychiatry 2004;75:857-862. doi: 10.1136/jnnp.2003.020479

See end of article for authors' affiliations

Correspondence to: Professor Heinrich P Mattle, Department of Neurology, University of Berne, Inselspital, $\mathrm{CH}-3010$

Berne, Switzerland; heinrich.mattle@insel.ch

Received 10 June 2003

In revised form 6 August 2003 Accepted

16 September 2003
Objective: To define predictors of recanalisation and clinical outcome of patients with acute basilar artery occlusions treated with local intra-arterial thrombolysis (IAT).

Methods: Vascular risk factors, severity of the neurological deficit graded by the National Institutes of Health stroke scale (NIHSS), and radiological findings were recorded at presentation. Outcome was measured using the modified Rankin scale (mRS) three months later and categorised as favourable (mRS 0-2), poor (mRS 3-5), or death (mRS 6).

Results: 40 patients were studied. Median NIHSS on admission was 18. Mean time from symptom onset to treatment was 5.5 hours (range 2.3 to 11 ). Outcome was favourable in 14 patients (35\%) and poor in nine $(23 \%) ; 17(42 \%)$ died. There were two symptomatic cerebral haemorrhages (5\%). Recanalisation of the basilar artery was achieved in 32 patients (80\%); it was complete (TIMI grade 3 ) in $20 \%$ and partial (TIMI grade 2 ) in $60 \%$. In multivariate logistic regression analysis, low NIHSS score on admission $(p=0.002)$ and vessel recanalisation $(p=0.005)$ were independent predictors of favourable outcome. Recanalisation occurred more often with treatment within six hours of symptom onset $(p=0.003)$ and when admission computed tomography showed a hyperdense basilar artery sign $(p=0.007)$. In a univariate model, quadriplegia $(p=0.002)$ and coma $(p=0.004)$ were associated with a poor outcome or death.

Conclusions: Low baseline NIHSS on admission and recanalisation of basilar artery occlusions predict a favourable outcome after intra-arterial thrombolysis. Early initiation of IAT and the presence of a hyperdense basilar artery sign on CT were associated with a higher likelihood of recanalisation.
A cute basilar artery occlusion is a serious condition which often results in severe disability or death. ${ }^{12}$ Several series have suggested that local intra-arterial thrombolysis (IAT) improves basilar artery recanalisation and clinical outcome. ${ }^{3-5}$ In these studies various thrombolytic agents and time windows to treatment were used. However, even with thrombolysis the prognosis remains poor in a large proportion of the patients, and whether to treat or withhold thrombolysis in a given patient is a crucial clinical question. To make such a decision some predictive variables may guide the clinician. To date, the variables reported to have influenced clinical outcome in previous case series have been heterogeneous. We therefore analysed the clinical findings and radiological data of our patients with acute stroke caused by basilar artery occlusion who had been treated with IAT within 12 hours of symptom onset, to identify factors that predict recanalisation and clinical outcome.

\section{METHODS}

We studied 40 consecutive patients with basilar artery occlusion treated with IAT using urokinase. Thirty two patients were treated at the university hospital of Berne from December 1992 to February 2002 and eight patients at the university hospital of Zurich from September 1997 to February 2002. Ten of the Bernese patients were described in an earlier report. ${ }^{6}$

Inclusion criteria for IAT in patients with suspected basilar artery occlusion were as follows:

- A clinical diagnosis of acute stroke established by a staff neurologist;
- computed tomography (CT) $(\mathrm{n}=37)$ or magnetic resonance imaging (MRI) $(\mathrm{n}=3)$, including $\mathrm{T} 2$ weighted, fast echo gradient, and diffusion weighted images, ruled out an intracranial haemorrhage;

- occlusion of the basilar artery documented by cerebral four vessel arteriography;

- expected initiation of treatment was within the first 12 hours of symptom onset;

- no clinical or laboratory contraindications for IAT;

- verbal informed consent of the patient or their relatives was obtained.

From January 1998 to February 2002, 27 patients with basilar artery occlusion were treated in the two hospitals (22 in Berne and five in Zurich) and nine were not (five in Berne and four in Zurich). The reasons why nine patients were not treated with IAT were as follows: time delay from symptom onset to admission $>12$ hours $(n=7)$; vertebral artery occlusion and contralateral vertebral artery hypoplasia preventing access to the occluded basilar artery $(n=2)$; and acute basilar artery occlusion after open heart surgery $(\mathrm{n}=1)$. Six patients in whom clinical findings suggested basilar artery occlusion had a normal angiogram. Before 1998 we did not record the data on all stroke patients and

Abbreviations: mRS, modified Rankin scale; NIHSS, National Institutes of Health stroke scale; TOAST, trial of Org 10172 in acute stroke treatment 
angiographies routinely; only those with acute stroke and intra-arterial thrombolysis were noted in a separate registry.

The National Institutes of Health stroke scale (NIHSS) scores on admission were assessed by a staff neurologist. ${ }^{7}$ Early CT signs of ischaemia were defined as parenchymal hypodensities in the vascular territory of the basilar artery and were evaluated by a staff neuroradiologist. A hyperdense basilar artery was defined as a hyperdense vessel on noncontrast CT compared visually with the density of other unaffected intracranial vessels. ${ }^{8}$ Selective intra-arterial digital subtraction angiography was undertaken from a transfemoral approach using a biplane, high resolution angiography system (Toshiba CAS 500, Tokyo, Japan) with a matrix of $1024 \times 1024$ pixels. All patients underwent complete four vessel cerebral arteriography to assess collateral flow and the length of the basilar artery occlusion. In four patients with unilateral vertebral artery hypoplasia and contralateral extracranial high grade vertebral artery stenosis, the stenosis was dilated at angioplasty, in two cases combined with deployment of a stent, in order to gain access to the occluded basilar artery.

The site of basilar artery occlusion was categorised according to the criteria described by Archer et al: caudal, from the confluence of the vertebral arteries to the anterior inferior cerebellar artery; mid-basilar, from the anterior inferior cerebellar artery to the superior cerebellar artery; and distal, distal to the superior cerebellar artery. ${ }^{2}$ The length of the basilar artery occlusion was defined as "short" if only one, and "long" if two or more segments of the basilar artery were not contrasted on the arteriogram. ${ }^{3}$

Collaterals were classified according to the criteria of Brandt et al: 0, no collaterals; 1 (minimal), antegrade or reversed partial or faint filling of collaterals; 2 (moderate), antegrade or reversed filling of the superior cerebellar arteries; and 3 (maximal), collaterals with antegrade and reversed filling or maximal bilateral filling of the superior cerebellar arteries. ${ }^{9}$ For thrombolyis we used a Fast Tracker (Target Therapeutics) microcatheter, which was advanced into the occluded vessel. Urokinase (HS Medac) in a mean dose of 872000 IU (range 20000 to 1250000 IU) was given directly into the clot or as close as possible to its proximal end over a period of 60 to 90 minutes. Recanalisation was documented by a control arteriogram done immediately after IAT and classified by a neuroradiologist according to thrombolysis in myocardial infarction (TIMI) grades ${ }^{10}$ as follows: TIMI grade 0 , no recanalisation; TIMI grade 1 , minimal recanalisation; TIMI grade 2 , partial recanalisation; TIMI grade 3, complete recanalisation.

After IAT, 21 patients received aspirin in a dose of 250 to $500 \mathrm{mg}$ a day. Nineteen patients, who had either been treated before publication of the international stroke trial results $^{11}$ or who had a residual high grade basilar artery stenosis on control arteriography after IAT, were given heparin in a therapeutic dose adjusted according to thrombin time. Control CT or MRI was undertaken routinely within 24 hours after IAT. In addition, CT was done in all patients where there was clinical deterioration. A symptomatic haemorrhage was defined as a homogeneous volume of blood associated with clinical deterioration. In two patients with massive cerebellar oedema a craniotomy was carried out. The aetiology of the ischaemic stroke was classified according to the TOAST criteria (trial of Org 10172 in acute stroke treatment), using additional investigations as necessary. ${ }^{12}$ Functional outcome at three months was evaluated by different neurologists and classified using the modified Rankin scale (mRS). ${ }^{13}$ The investigators were not blinded to the baseline scores and angiographic results.

\section{Statistics}

Statistical analysis was carried out using SPSXX 10 for Macintosh statistical software (SPSS Inc, Chicago, Illinois, USA). Predictors of outcome were analysed by comparing patients with a functional outcome of mRS 0 to 2 (favourable outcome) with those with a functional outcome of 3 to 6 ( 3 to 5 , poor outcome; 6 , death). For analysis of the time variable, patients were grouped into those treated within $\leqslant 6$ and $>6$ hours of symptom onset; and to examine collateral circulation patients were dichotomised according to whether they had sufficient collaterals (grade 2 or 3 ) or insufficient collaterals (grade 0 and 1). To determine predictors of recanalisation, TIMI recanalisation grades 0 and 1 were defined as inadequate recanalisation and TIMI grades 2 and 3 as adequate recanalisation. The $\chi^{2}$ test was used for cross tabulation. Forward stepwise logistic regression analyses were carried out on the predictive factors identified by univariate analysis.

\section{RESULTS \\ Demographic, clinical, and radiological data}

Forty patients (22 men, 18 women) with a mean (SD) age of 58 (15) years (median 60, range 28 to 78 ) were treated. The median NIHSS score on admission was 18 (range 5 to 38 ). Thrombolysis was initiated on average 5.5 hours after symptom onset (range 2.3 to 11 hours). Sixteen patients had quadriplegia and 15 were comatose before IAT. There were early CT signs of ischaemia in the basilar artery territory in 10 of 37 patients $(27 \%)$. A hyperdense basilar artery sign was seen on 26 of the 37 admission CT investigations (70\%). Twenty patients $(50 \%)$ had caudal, $13(32 \%)$ midbasilar, and seven (18\%) distal basilar artery occlusions. Seventeen patients had a short and 23 a long occlusion. The demographic, clinical, and radiological findings are summarised in tables 1 and 2 .

\section{Clinical outcome and its predictors}

At three months, outcome was favourable (mRS $\leqslant 2$ ) in 14 patients (35\%) and poor (mRS 3 to 5 ) in nine $(23 \%)$. Seventeen patients $(42 \%)$ died (fig 1 ). The causes of death were failure of brain stem functions in eight, withdrawal of care in seven, and pneumonia in two.

In a univariate model, a baseline NIHSS score of $>20$ $(p<0.0001)$, quadriplegia $(p=0.002)$, and coma on admission $(p=0.004)$ were clinical predictors of poor outcome or death. There was no significant association of age, sex, time to treatment, vascular risk factors, or stroke aetiology with clinical outcome (table 1). However, a trend was observed favouring patients treated within six hours of symptom onset, compared with those with later initiation of treatment (41\% v 18\% favourable outcome).

The only radiological predictor of favourable outcome was partial or complete recanalisation as seen on arteriography after IAT. All eight patients without or with minimal recanalisation had a poor outcome or died, whereas the outcome of 14 of 32 patients (44\%) with partial or complete recanalisation was favourable $(p=0.02)$. Patients with sufficient collaterals showed a non-significant trend towards a better outcome (table 2). A hyperdense basilar artery sign on the admission CT scan, early CT signs of ischaemia, and localisation and length of basilar artery occlusions were not predictive of the clinical outcome.

After multivariate analysis, NIHSS score on admission $(p=0.002)$ and vessel recanalisation $(p=0.005)$ remained independent variables predicting outcome.

\section{Recanalisation and predictors of recanalisation}

Thrombolysis recanalised eight $(20 \%)$ of the occluded basilar arteries completely, and $24(60 \%)$ partially. Complete or 


\begin{tabular}{|c|c|c|c|c|c|}
\hline \multirow[b]{2}{*}{ Characteristic } & \multicolumn{2}{|l|}{ Outcome } & \multirow[b]{2}{*}{$\begin{array}{l}\mathrm{p} \text { Value } \\
\text { univariate }\end{array}$} & \multirow[b]{2}{*}{$\begin{array}{l}\mathrm{p} \text { Value } \\
\text { multivariate }\end{array}$} & \multirow[b]{2}{*}{ Total (n) } \\
\hline & $\begin{array}{l}\text { Favourable } \\
\text { (mRS 0-2) }\end{array}$ & $\begin{array}{l}\text { Poor or death } \\
\text { (mRS 3-6) }\end{array}$ & & & \\
\hline No of patients & $14(35 \%)$ & $26(65 \%)$ & & & 40 \\
\hline Age $\leqslant 60$ & $9(45 \%)$ & 11 (55\%) & & & 20 \\
\hline Age $>60$ & $5(25 \%)$ & $15(75 \%)$ & NS & & 20 \\
\hline \multicolumn{6}{|l|}{ Sex } \\
\hline Male & $7(32 \%)$ & $15(68 \%)$ & & & 22 \\
\hline Female & $7(39 \%)$ & $11(61 \%)$ & NS & & 18 \\
\hline \multicolumn{6}{|l|}{ Diabetes } \\
\hline Yes & $0(0 \%)$ & $1(100 \%)$ & & & 1 \\
\hline No & $14(37 \%)$ & $24(63 \%)$ & NS & & 38 \\
\hline \multicolumn{6}{|l|}{ Smoking } \\
\hline Yes & $4(31 \%)$ & $9(69 \%)$ & & & 13 \\
\hline No & $10(38 \%)$ & $16(62 \%)$ & NS & & 26 \\
\hline \multicolumn{6}{|l|}{ Hypercholesterolaemia } \\
\hline Yes & $4(31 \%)$ & $9(69 \%)$ & & & 13 \\
\hline No & $10(38 \%)$ & $16(62 \%)$ & NS & & 26 \\
\hline \multicolumn{6}{|l|}{ Hypertension } \\
\hline Yes & $5(26 \%)$ & $14(74 \%)$ & & & 19 \\
\hline \multirow{2}{*}{\multicolumn{6}{|c|}{ NIHSSS on admission }} \\
\hline & & & & & \\
\hline$\leqslant 220$ & $13(59 \%)$ & $9(41 \%)$ & & & 22 \\
\hline$>20$ & $1(6 \%)$ & $17(94 \%)$ & $<0.0001$ & 0.002 & 18 \\
\hline \multicolumn{6}{|l|}{ Coma } \\
\hline Yes & $1(7 \%)$ & $14(93 \%)$ & & & 15 \\
\hline No & $13(52 \%)$ & $12(48 \%)$ & 0.004 & NS & 25 \\
\hline \multicolumn{6}{|l|}{ Quadriplegia } \\
\hline Yes & $1(6 \%)$ & $15(94 \%)$ & & & 16 \\
\hline No & $13(54 \%)$ & $11(46 \%)$ & 0.002 & NS & 24 \\
\hline \multicolumn{6}{|l|}{ Time to treatment } \\
\hline$\leqslant 6$ hours & $12(41 \%)$ & $17(59 \%)$ & & & 29 \\
\hline$>6$ hours & $2(18 \%)$ & $9(82 \%)$ & NS & NS & 11 \\
\hline \multicolumn{6}{|l|}{ Stroke aetiology } \\
\hline Cardioembolic & $6(50 \%)$ & $6(50 \%)$ & & & 12 \\
\hline Unknown & $2(20 \%)$ & $8(80 \%)$ & NS & NS & 10 \\
\hline Large artery disease & $4(29 \%)$ & $10(71 \%)$ & & & 14 \\
\hline VA dissection & $2(50 \%)$ & $2(50 \%)$ & & & 4 \\
\hline
\end{tabular}

partial recanalisation was more frequent in patients treated within six hours than in those treated between six and 12 hours after symptom onset $(90 \% v 55 \%, p=0.011)$. On univariate analysis the presence of a hyperdense basilar artery sign on CT was associated with a greater likelihood of recanalisation $(p=0.022)$. Age, sex, stroke aetiology, NIHSS score on admission, quadriplegia, coma, early CT signs of ischaemia, localisation and length of basilar artery occlusion, and collaterals did not predict recanalisation. The demographic, clinical, and radiological findings and their

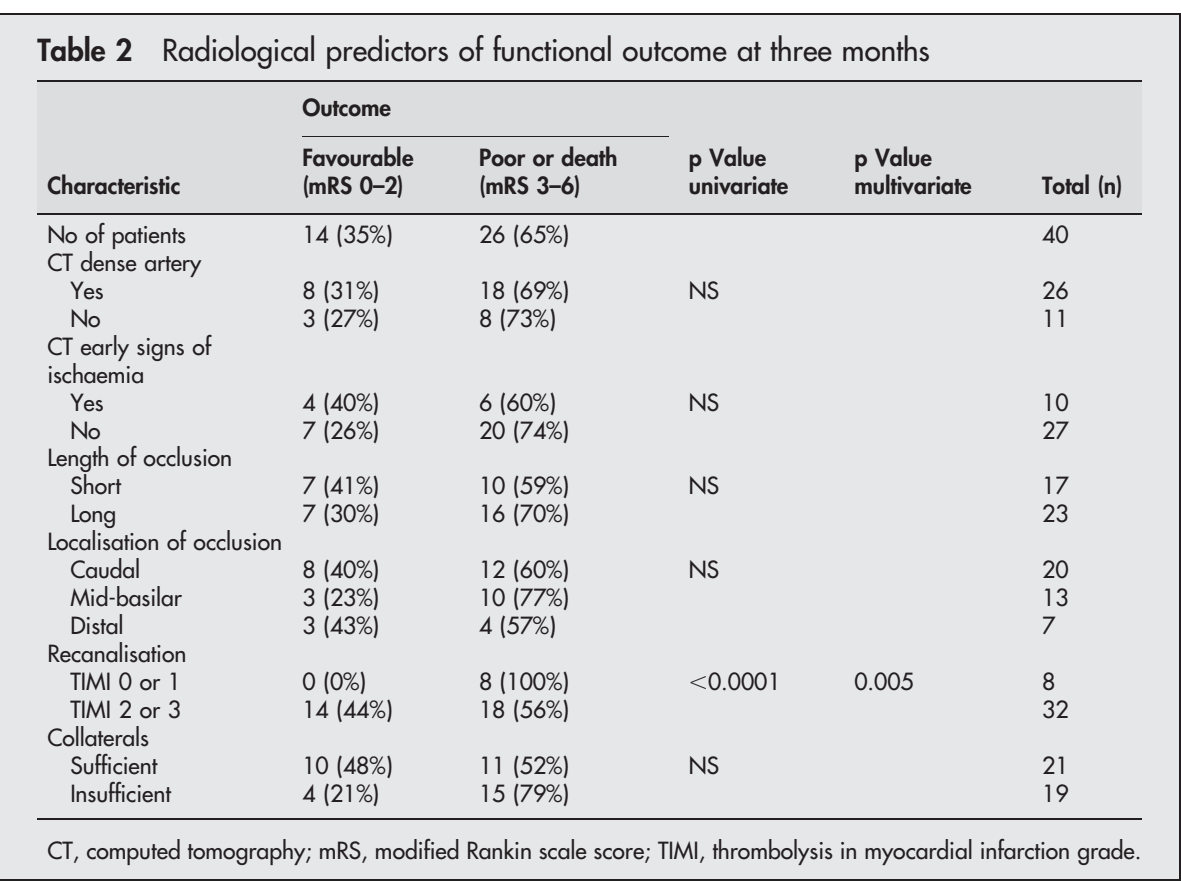




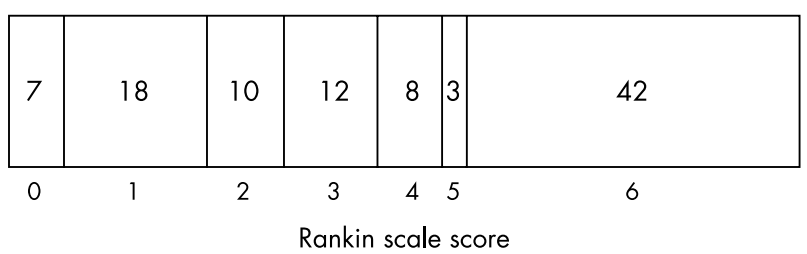

Figure 1 Outcome according to the modified Rankin scale (RS) at three months. Values are percentages.

correlations with recanalisation are summarised in tables 3 and 4.

On multivariate analysis recanalisation was more likely with treatment within six hours of symptom onset $(p=0.003)$ and when admission CT showed a dense basilar artery $\operatorname{sign}(p=0.007)$.

\section{Late recanalisation}

In eight patients $(20 \%)$ recanalisation of the basilar artery could not be achieved while they were in the angiography suite. Four patients died soon afterwards and did not have any vascular follow up investigations. Three patients were investigated by follow up transcranial Doppler within the first week. In one, the basilar artery was still occluded, and in two it was partially recanalised. A fourth patient underwent MR angiography on day 7 . His basilar artery was partially recanalised.

\section{Complications}

Two patients $(5 \%)$ suffered a symptomatic intracerebral haemorrhage within 24 hours after IAT and died. Two additional patients ( $5 \%$ ) developed a local haematoma at the catheter insertion site in the femoral artery. They did not require transfusions or any other intervention.

\section{DISCUSSION}

\section{Outcome}

The course of basilar artery occlusion, with or without the use of antithrombotic agents, is usually poor. ${ }^{2}$ Only a few cases with spontaneous favourable outcomes have been reported. ${ }^{9}$
Intra-arterial thrombolysis improved survival and recanalisation compared with historical controls. ${ }^{3}$ It may also improve the clinical outcome. ${ }^{5}$ In this series $58 \%$ of the patients with basilar artery occlusion treated with IAT survived. In the series as a whole, $35 \%$ had a favourable clinical outcome. Most of previously published series using different thrombolytic agents, selection criteria, and treatment windows up to more than 48 hours after symptom onset reported a higher mortality and less favourable outcomes (table 5)..$^{3-5}{ }^{14-16}$ One potential reason for the moderately better results of this series could have been the earlier treatment after symptom onset and the higher dose of thrombolytic agents (mean urokinase dose $872000 \mathrm{IU}$ ), which recanalised $80 \%$ of the occluded basilar arteries partially or completely.

\section{Predictors of favourable outcome}

A low NIHSS score on admission in this series predicted a favourable outcome, consistent with observations of thrombolysis in the carotid territory. ${ }^{17-19}$ In a univariate analysis, patients with quadriplegia $(p=0.002)$ or coma before thrombolysis $(\mathrm{p}=0.004$ ) were more likely to have a poor outcome than those without these signs. Decreased consciousness has been a predictor of unfavourable outcome in other series as well. ${ }^{14}$ On multivariate analysis, however, coma and quadriplegia no longer had any predictive value because of the interaction with the NIHSS score. All patients with coma and quadriplegia have high NIHSS scores, and mostly such patients die or remain severely disabled. Exceptionally, comatose and quadriplegic patients recover, as did one patient in our study who had been comatose and quadriplegic for one hour before IAT and recovered to an mRS score of 2. In a series of Wijdicks et al, two patients with locked in syndrome lasting for several hours recovered fully after successful thrombolysis. ${ }^{20}$ Thus in our opinion, patients with coma and quadriplegia should not be excluded from IAT, although a poor outcome is more likely.

In this study IAT was undertaken on average five and a half hours after symptom onset. The earlier the treatment was initiated, the more likely was the occluded artery to recanalise. However, this did not result in clinical benefit. There was only a non-significant trend towards better clinical

\begin{tabular}{|c|c|c|c|c|c|}
\hline \multirow[b]{2}{*}{ Characteristic } & \multicolumn{2}{|c|}{ Recanalisation } & \multirow{2}{*}{$\begin{array}{l}\text { p Value } \\
\text { univariate }\end{array}$} & \multirow{2}{*}{$\begin{array}{l}\mathrm{p} \text { Value } \\
\text { multivariate }\end{array}$} & \multirow[b]{2}{*}{ Total (n) } \\
\hline & TIMI 0 or 1 & TIMI 2 or 3 & & & \\
\hline No of patients & $8(20 \%)$ & $32(80 \%)$ & \multirow{3}{*}{ NS } & & 40 \\
\hline Age $\leqslant 60$ & $5(25 \%)$ & $15(75 \%)$ & & & 20 \\
\hline Age $>60$ & $3(15 \%)$ & $17(85 \%)$ & & & 20 \\
\hline \multicolumn{6}{|l|}{ Sex } \\
\hline Male & $2(10 \%)$ & $20(90 \%)$ & \multirow[t]{2}{*}{ NS } & & 22 \\
\hline Female & $6(33 \%)$ & $12(67 \%)$ & & & 18 \\
\hline \multicolumn{6}{|c|}{ NIHSSS on admission } \\
\hline$\leqslant 20$ & $4(22 \%)$ & $18(78 \%)$ & \multirow[t]{2}{*}{ NS } & & 22 \\
\hline$>20$ & $4(29 \%)$ & $14(71 \%)$ & & & 18 \\
\hline \multicolumn{6}{|l|}{ Coma } \\
\hline Yes & $5(33 \%)$ & $10(66 \%)$ & \multirow[t]{2}{*}{ NS } & & 15 \\
\hline No & $3(12 \%)$ & $22(88 \%)$ & & & 25 \\
\hline \multicolumn{6}{|l|}{ Quadriplegia } \\
\hline Yes & $5(31 \%)$ & $11(69 \%)$ & \multirow[t]{2}{*}{ NS } & & 16 \\
\hline No & $3(12 \%)$ & $21(88 \%)$ & & & 24 \\
\hline \multicolumn{6}{|l|}{ Time to treatment } \\
\hline$\leqslant 6$ hours & $3(10 \%)$ & $26(90 \%)$ & \multirow{2}{*}{0.011} & \multirow[t]{2}{*}{0.003} & 29 \\
\hline$>6$ hours & $5(45 \%)$ & $6(55 \%)$ & & & 11 \\
\hline \multicolumn{6}{|l|}{ Stroke aetiology } \\
\hline Cardioembolic & $1(9 \%)$ & 11 (91\%) & \multirow{4}{*}{ NS } & & 12 \\
\hline Unknown & $2(20 \%)$ & $8(80 \%)$ & & & 10 \\
\hline Large artery disease & $3(21 \%)$ & $11(79 \%)$ & & & 14 \\
\hline VA dissection & $2(50 \%)$ & $2(50 \%)$ & & & 4 \\
\hline
\end{tabular}


Table 4 Radiological predictors of recanalisation

\begin{tabular}{|c|c|c|c|c|c|}
\hline \multirow[b]{2}{*}{ Characteristic } & \multicolumn{2}{|c|}{ Recanalisation } & \multirow{2}{*}{$\begin{array}{l}\mathrm{p} \text { Value } \\
\text { univariate }\end{array}$} & \multirow{2}{*}{$\begin{array}{l}\text { p Value } \\
\text { multivariate }\end{array}$} & \multirow[b]{2}{*}{ Total (n) } \\
\hline & TIMI 0 or 1 & TIMI 2 or 3 & & & \\
\hline Dense artery (n) & $8(20 \%)$ & $32(80 \%)$ & & & 40 \\
\hline \multicolumn{6}{|l|}{$\mathrm{CT}$ dense artery } \\
\hline Yes & $3(12 \%)$ & $23(88 \%)$ & \multirow[t]{2}{*}{0.022} & \multirow[t]{2}{*}{0.007} & 26 \\
\hline No & $5(45 \%)$ & $6(55 \%)$ & & & 11 \\
\hline \multicolumn{6}{|c|}{$\mathrm{CT}$ early signs of ischaemia } \\
\hline Yes & $1(10 \%)$ & $9(90 \%)$ & \multirow[t]{2}{*}{ NS } & & 10 \\
\hline No & $7(26 \%)$ & $20(74 \%)$ & & & 27 \\
\hline \multicolumn{6}{|c|}{ Length of occlusion } \\
\hline Short & $2(12 \%)$ & $15(88 \%)$ & \multirow[t]{2}{*}{ NS } & & 17 \\
\hline Long & $6(26 \%)$ & $17(74 \%)$ & & & 23 \\
\hline \multicolumn{6}{|c|}{ Localisation of occlusion } \\
\hline Caudal & $5(25 \%)$ & $15(75 \%)$ & \multirow[t]{3}{*}{ NS } & & 20 \\
\hline Mid-basilar & $3(23 \%)$ & 10 (77\%) & & & 13 \\
\hline Distal & $0(0 \%)$ & $7(100 \%)$ & & & 7 \\
\hline \multicolumn{6}{|l|}{ Collaterals } \\
\hline Sufficient & $4(19 \%)$ & $17(81 \%)$ & \multirow[t]{2}{*}{ NS } & & 21 \\
\hline Insufficient & $4(27 \%)$ & $15(73 \%)$ & & & 19 \\
\hline
\end{tabular}

outcome in patients treated earlier. On the other hand, there are reports of patients with favourable outcomes who had been treated quite late after symptom onset. ${ }^{41}$ These observations are most probably explained by collateral vessels which preserve the ischaemic tissue at risk of irreversible cell death for a prolonged period. In some series there was a significant association between collaterals and survival. ${ }^{5}{ }^{15}$ In this series, a non-significant trend supports this hypothesis as well. Forty eight per cent of patients with adequate collaterals versus $21 \%$ with inadequate collaterals had a favourable outcome. Possibly collaterals that are adequate to preserve tissue at risk for a prolonged period are not always visualised on arteriography, and other methods will be needed to identify patients with salvageable tissue. Pretreatment diffusion and perfusion MRI might help in deciding more accurately than arteriography which patients will benefit from recanalising treatment even after longer time windows. ${ }^{21}$

There was no correlation between age, sex, or vascular risk factors and outcome. A hyperdense basilar artery sign on the admission CT, early CT signs of ischaemia, localisation and length of the basilar artery occlusion, and the presence of collaterals failed to predict the clinical outcome.

\section{Recanalisation and predictors of recanalisation}

Partial or complete recanalisation was achieved in $80 \%$ of the patients in this series and in $44 \%$ to $75 \%$ in other studies (table 5). In contrast to other series, a shorter delay to treatment rendered recanalisation more probable in our patients. ${ }^{5}$ In addition, a hyperdense basilar artery sign on the initial CT increased the chances of recanalisation.
Embolic clots in a previously unaffected artery may be more likely to appear as a hyperdense basilar artery sign on CT than a clot formed in a pre-existing high grade atherothrombotic basilar artery stenosis, and embolic occlusions might also be more easily recanalised than a thrombosis on an arteriosclerotic vessel wall. Such an interpretation is supported by the finding of other studies that cardioembolic occlusions had higher recanalisation rates than occlusions of other aetiology. ${ }^{52}$ However, in our series there was no association between a hyperdense basilar artery sign on CT and a cardioembolic origin of the clot. This could partly reflect the large proportion of stroke of undetermined origin, because many patients died before they could undergo ancillary investigations such as echocardiography.

\section{Complications}

Two symptomatic intracerebral haemorrhages occurred. Other studies have also reported low rates of symptomatic haemorrhagic complications in the vertebrobasilar territory. These findings and our results from retrospective analysis of patient series indicate that IAT for basilar artery occlusion is fairly safe when undertaken by an experienced stroke team. ${ }^{35}$

\section{Conclusions}

The results of this study and previous series suggest that IAT may be beneficial for selected patients with basilar artery occlusion. A favourable clinical outcome in this study was more common in patients with low NIHSS score before treatment and when recanalisation was achieved. Initiation of IAT within six hours of symptom onset and hyperdense basilar artery sign on CT indicated a greater chance of

Table 5 Review of published reports on recanalisation and outcome of patients with basilar artery occlusion treated with thrombolysis

\begin{tabular}{|c|c|c|c|c|c|}
\hline Source & $\begin{array}{l}\text { No of patients } \\
\text { (mode of treatment) }\end{array}$ & Maximum time window & $\begin{array}{l}\text { Partial or complete } \\
\text { recanalisation (n (\%)) }\end{array}$ & Favourable outcome (n (\%)), measured by: & Survival (n (\%)) \\
\hline Hacke $^{3}$ & 43 (ia) & $>72$ hours & $19(44 \%)$ & $10(23 \%)$ (no, minimal, or moderate deficit) & $14(33 \%)$ \\
\hline Zeumer $^{4}$ & 28 (ia) & $\begin{array}{l}\text { Not indicated (mean } 8 \\
\text { hours) }\end{array}$ & $21(75 \%)$ & $10(35 \%)$ (able to work) & $18(64 \%)$ \\
\hline Becker $^{14}$ & 12 (ia) & 48 hours & $9(75 \%)$ & $3(25 \%)$ (minimal deficits) & $3(25 \%)$ \\
\hline Brandt ${ }^{5}$ & 42 (ia)/9 (iv) & 48 hours & $26(51 \%)$ & $10(20 \%)$ (Barthel $\geqslant 95)$ & $16(31 \%)$ \\
\hline Cross $^{15}$ & 24 (ia) & 82 hours & Not indicated & $6(25 \%)(m R S \leqslant 2)$ & $9(38 \%)$ \\
\hline Huemer $^{16}$ & 16 (iv) & 7 hours & $10(62 \%)$ & $\begin{array}{l}3 \text { (19\%) (independence from constant } \\
\text { support) }\end{array}$ & $5(31 \%)$ \\
\hline Present study & 40 (ia) & 12 hours & $32(80 \%)$ & $14(35 \%)(\mathrm{mRS} \leqslant 2)$ & $23(58 \%)$ \\
\hline
\end{tabular}


recanalisation. When patients are in coma, quadriplegic, or have already had prolonged symptoms, the decision about whether to attempt IAT or to withhold treatment can be difficult. In such patients, MRI with diffusion and perfusion imaging might help to identify those who are most likely to benefit from IAT. ${ }^{21}$ In addition, other techniques and agents to treat basilar artery occlusion might result in better outcomes and need to be studied. These include combined intravenous and intra-arterial thrombolysis, mechanical thrombaspiration and fragmentation, and other antithrombotic agents such as abciximab or tirofiban (alone or in combination with thrombolytics), mechanical recanalisation including thrombus aspiration, primary angioplasty, and stenting of the basilar artery. ${ }^{23-31}$

\section{ACKNOWLEDGEMENTS}

We thank Pietro Ballinari PhD for statistical advice. The study was supported by a grant from the Stiftung zur Förderung der Wissenschaftlichen Forschung an der Universität Bern.

\section{Authors' affiliations}

G Schroth, L Remonda, Department of Diagnostic and Interventional

Neuroradiology, University of Berne, Berne, Switzerland

R W Baumgartner, Department of Neurology, University of Zurich, Zurich, Switzerland

B Schuknecht, Department of Neuroradiology, University of Zurich

M Arnold, K Nedeltchev, T J Loher, F Stepper, M Sturzenegger,

H P Mattle, Department of Neurology, University of Berne

Competing interests: none declared

\section{REFERENCES}

1 Castaigne $\mathbf{P}$, Lhermitte F, Gautier JC, et al. Arterial occlusions in the vertebrobasilar system: a study of 44 patients with post-mortem data. Brain 1973:96:133-54.

2 Archer CR, Horenstein S. Basilar artery occlusion: clinical and radiological correlation. Stroke 1977;8:383-90.

3 Hacke W, Zeumer $\mathrm{H}$, Ferbert A, et al. Intra-arterial thrombolytic therapy improves outcome in patients with acute vertebrobasilar occlusive disease. Stroke 1988;19:1216-22

4 Zeumer H, Freitag HJ, Grzyska U, et al. Local intra-arterial fibrinolysis in acute vertebrobasilar occlusion. Neuroradiology 1989;31:336-40.

5 Brandt T, von Kummer R, Müller-Küppers $M$, et al. Thrombolytic therapy of acute basilar artery occlusion. Stroke 1996:27:875-81.

6 Gönner F, Remonda L, Mattle H, et al. Local intra-arterial thrombolysis in acute ischemic stroke. Stroke 1998;29:1894-900.

7 Brott T, Adams HP Jr, Olinger CP, et al. Measurements of acute cerebral infarction: a clinical examination scale. Stroke 1989;20:846-70.

8 Harrington $\mathrm{T}$, Roche J. The dense basilar artery as a sign of basilar territory infarction. Australas Radiol 1993;37:375-8.

9 Brandt T, Pessin MS, Kwan ES, et al. Survival with basilar artery occlusion. Cerebrovasc Dis 1995;5:182-7.

10 The Thrombolysis in Myocardial Infarction (TIMI) trial. Phase I findings. TIMI Study Group. N Engl J Med 1985;312:932-6.
11 The International Stroke Trial (IST): a randomized trial of aspirin, subcutaneous heparin, both, or neither among 19435 patients with acute ischaemic stroke. International Stroke Trial Collaborative Group. Lancet 1997;349:1569-81.

12 Adams HP, Bendixen BH, Kappelle $\sqcup$, et al. the TOAST investigators. Classification of subtype of acute ischemic stroke. Definitions for use in a multicenter clinical trial. TOAST. Trial of Org 10172 in Acute Stroke Treatment. Stroke 1993;24:35-41.

13 van Swieten JC, Koudstaal PJ, Visser MC, et al. Interobserver agreement for the assessment of handicap in stroke patients. Stroke 1988;19:604-7.

14 Becker KJ, Monsein LH, Ulatowski J, et al. Intraarterial thrombolysis in vertebrobasilar occlusion. AJNR Am J Neuroradiol 1996;17:255-62.

15 Cross DT, Moran CJ, Akins PT, et al. Collateral circulation and outcome after basilar artery thrombolysis. AJNR Am J Neuroradiol 1998;19:1557-63.

16 Huemer M, Niederwieser V, Ladurner G. Thrombolytic treatment for acute occlusion of the basilar artery. J Neurol Neurosurg Psychiatry 1995:58:227-8.

17 Ueda T, Sakaki S, Kumon Y, et al. Multivariable analysis of predictive factors related to outcome at 6 months after intra-arterial thrombolysis for acute ischemic stroke. Stroke 1999;30:2360-5.

18 Trouillas P, Nighoghossian N, Derex L, et al. Thrombolysis with intravenous rPA in a series of 100 cases of acute carotid territory stroke: determination of etiological, topographic, and radiological outcome factors. Stroke 1998;29:2529-40.

19 Arnold M, Schroth G, Nedeltchev K, et al. Intra-arterial thrombolysis in 100 patients with acute stroke due to middle cerebral artery occlusion. Stroke 2002;33:1828-33.

20 Wijdicks EF, Nichols DA, Thielen KR, et al. Intra-arterial thrombolysis in acute basilar artery thromboembolism: the initial Mayo Clinic experience. Mayo Clin Proc 1997;72:1005-13.

21 du Mesnil de Rochemont R, Neumann-Haefelin T, Berkefeld J, et al. Magnetic resonance imaging in basilar artery occlusion. Arch Neurol 2002:59:398-402.

22 Sliwka U, Mull M, Stelzer A, et al. Long-term follow-up of patients after intraarterial thrombolytic therapy of acute vertebrobasilar artery occlusion. Cerebrovasc Dis 2001;12:214-19.

23 Lewandowski CA, Frankel M, Tomsick TA, et al. Combined intravenous and intra-arterial $r$-TPA versus intra-arterial therapy of acute ischemic stroke: Emergency Management of Stroke (EMS) Bridging Trial. Stroke 1999;30:2598-605.

24 Ernst R, Pancioli A, Tomsick T, et al. Combined intravenous and intra-arterial recombinant tissue plasminogen activator in acute ischemic stroke. Stroke 2000;31:2552-7.

25 Keris V, Rudnicka S, Vorona V, et al. Combined intra-arterial/intravenous thrombolysis for acute ischemic stroke. Am J Neuroradiol 2001 22:352-8.

26 Chapot R, Houdart E, Rogopoulos A, et al. Thromboaspiration in the basilar artery: report of two cases. Am J Neuroradiol 2002;23:282-4.

27 Mayer TE, Hamann GF, Brueckmann H. Mechanical extraction of a basilarartery embolus with the use of flow reversal and a microbasket. N Engl J Med 2002;347:769-70.

28 Eckert B, Koch C, Thomalla G, et al. Acute basilar artery occlusion treated with combined intravenous abciximab and intra-arterial tissue plasminogen activator: report of 3 cases. Stroke 2002;33:1424-7.

29 Junghans U, Seitz RJ, Wittsack HJ, et al. Treatment of acute basilar artery thrombosis with a combination of systemic alteplase and tirofiban, a nonpeptide platelet glycoprotein Ilb/llla inhibitor: report of four cases. Radiology 2001;221:795-801.

30 Spreer J, Els T, Hetzel A, et al. Primary stenting as emergency therapy in acute basilar artery occlusion. Neuroradiology 2002;44:791-5.

31 Phatouros CC, Higashida RT, Malek AM, et al. Endovascular stenting of an acutely thrombosed basilar artery: technical case report and review of the literature. Neurosurgery 1999;44:667-73. 